\title{
SELF-TUNING NEURO-FUZZY GENERALIZED MINIMUM VARIANCE CONTROLLER
}

\author{
Sergio E. Pinto Castillo ${ }^{1}$, Mike J. Grimble ${ }^{2}$ and Reza Katebi ${ }^{2}$ \\ ${ }^{1,2}$ Industrial Control Centre, University of Strathclyde, \\ Graham Hills Building, 50 George Street, \\ Glasgow, G1 1QE, UK \\ ${ }^{1}$ Engineering Department, Autonomous University of Tlaxcala, \\ Calzada Apizaquito S/N, Apizaco, Tlaxcala, MX
}

\begin{abstract}
The development of a Self-Tuning Neuro-Fuzzy Generalized Minimum Variance (GMV) controller is described. It uses fuzzy expert knowledge of the dynamic weightings to meet desired closed-loop stability and performance requirements. The controller is formulated in a polynomial system approach mixed with a Neuro-Fuzzy model and Fuzzy Self-Tuning mechanism. The proposed method is applied to a model of the Continuous Stirred Tank Reactor with Cooling Jacket and is compared with a PI controller, GMV controller with the correct model and a Fuzzy-PI controller. Simulation results are presented to demonstrate the performance of the proposed method. Copyright (C) 2005 IFAC
\end{abstract}

Keywords: Self-Tuning Control, Neuro-Fuzzy Modeling, Nonlinear Control.

\section{INTRODUCTION}

The polynomial approach was used to develop the Minimum Variance (MV) controller in the 60's. This included a colored noise disturbance signal and was suitable in different forms for minimum and nonminimum phase systems (Åström , 1979). The GMV controller including an additional costing term of the control signal was developed by Clarke and HastingsJames (Hastings-James, 1970; Clark and HastingsJames, 1971). Clark and Gawthrop introduced the GMV Self-Tuning controller which took advantage of the characteristics above mentioned (Clark and Gawthrop, 1975). Grimble used a GMV structure in order to control nonminimum phase systems in (Grimble, 1981). Additionally, Grimble designed linear systems using GMV control laws (Grimble, 1988). This was followed by the Generalized $\mathrm{H}_{\infty}$ controller obtaining a dynamic costing solution using the dynamic cost weightings (Grimble, 1994).

Up to this point, all the algorithms were applied to stochastic linear systems in the discrete time domain. Founded on these ideas, Grimble developed the GMV controller for nonlinear multivariable processes with time varying properties (Grimble, 2003). This had the structure of the Smith Predictor and therefore could be called a Nonlinear Smith Predictor.

Fuzzy Logic has been applied in many areas with success. It is a qualitative representation of the natural process using fuzzy rules (Pinto, 2001b). Fuzzy identification uses also fuzzy rules to identify the objective model. This model has been used to control plants using adaptive Neuro-Fuzzy (NF) controllers and models (Jang, et. all., 1997; Babuška, 1998). The Tuning of controllers always represent a challenge because it is usually heuristic and trail-error based. The fuzzy tuning mechanism has been reported before in some previous works in order to tune several types of controllers (He et all. , 1993; Molengraft, 1995; Wang , 1997; Mudi and Nikhil ,1999; Pinto ,2001a; Babuška et. all., 2002). The advantages of these structures are the capacity to adapt the parameters of the controller to the changes of the parameters of the plant and also save time in the process of tuning the controller. 
The main contribution of this article is to design and apply the Self-Tuning Neuro-Fuzzy GMV (STNFGMV), which uses the fuzzy expert knowledge of dynamical weightings (Error Weighting and Control Weighting) to tune the controllers. Also, other important feature of this controller is that we only need input-ouput data of the plant in order to identify the nonlinear model. This controller is based on a polynomial system approach mixed with the NeuroFuzzy (NF) model and the Fuzzy Self-Tuning Mechanism. The STNFGMV is applied to a model of the Continuous Stirred Tank Reactor with Cooling Jacket and is compared with a PI controller, GMV controller with the correct model and the Fuzzy-PI controller heuristically designed and used in (Mudi and Pal Nikhil ,1999; Pinto 2001a, 2001b). Also this controller gives us the possibility to control nonlinear systems with delay. Simulation results are presented to demonstrate the performance of the proposed method.

\section{STNFGMV CONTROLLER}

The STNFGMV controller has a structure formed by the Neuro-Fuzzy GMV controller and the Fuzzy Self Tuning Mechanism. The general structure of the STNFGMV is shown in Figure 1. This NFGMV is a hybrid controller that mixes the stochastic control (controller colored by white noise zero-mean) with the NF modeling.

In addition, the NF modeling is a hybrid intelligent system, it mixes two concepts of the artificial intelligent as Artificial Neural Networks (ANN) and Fuzzy Logic (Jang, et. all., 1997; Babuška, 1998). The hybrid algorithm takes advantage of the individual characteristics of the ANN and FL in order to make the physical meaning clear, using the fuzzy rules and the acquisition of the expert knowledge by the training as an ANN. To tune the NFGMV controller by trial and error, much time was spent in order to find appropriate values for the control weighting $P_{c}$.and error weighting $F_{c}$.

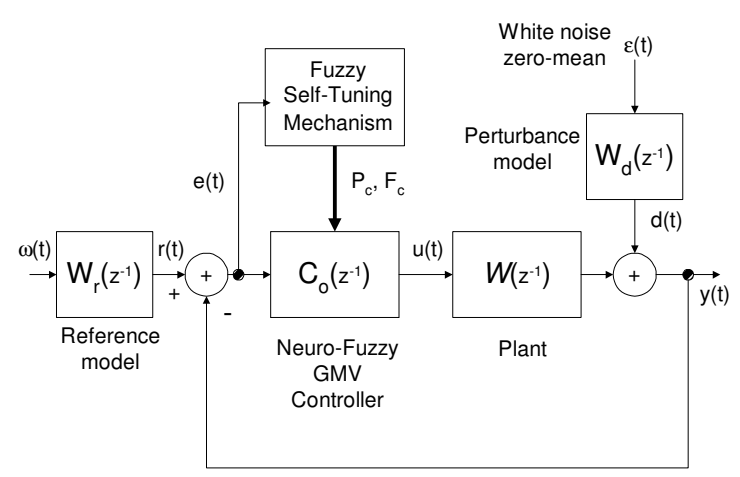

Fig. 1. General Structure of the Self-Tuning NeuroFuzzy Generalized Minimum Variance Controller

\section{MODELS AND SIGNALS PRESENT IN GMV}

The polynomial models of system are defined by the next equation:

$$
\left[W_{d}, W_{r}, W_{o k}\right]=A^{-1}\left[C_{d}, E_{r}, B_{o k}\right]
$$

where $W_{d}, W_{r}$ and $W_{o k}$ are the disturbance, reference models and linear part of nonlinear plant respectively. In addition $A, C_{d}, E_{r}, B_{o k}$ are polynomials in the forward shift operator $\left(z^{-1}\right)$ without any common factors. All the analysis and mathematical development are included in (Grimble, 2003). The nonlinear timevarying plant model:

$$
y(t)=(W u)(t)=D_{k}\left(W_{k} u\right)(t)
$$

and

$$
W_{k}=W_{o k}=A^{-1} B_{o k} W_{1 k}
$$

where $D_{k}$ is delay of the nonlinear plant and $W_{o k}$ is a stable/unstable linear time invariant block with any unstable modes of the nonlinear plants.

The pseudo output function $\phi_{o}(t)$ is:

$$
\phi_{o}(t)=P_{c} e(t)+F_{c} u(t)
$$

where $P_{c}$ and $F_{c}$ are the control weighting and error weighting. They are defined with the polynomial structure as:

$$
P_{c}\left(z^{-1}\right)=P_{c d}^{-1}\left(z^{-1}\right) P_{c n}\left(z^{-1}\right)
$$

and

$$
F_{c}\left(z^{-1}\right)=D_{k} F_{c k}\left(z^{-1}\right)=D_{k} F_{c d}^{-1}\left(z^{-1}\right) F_{c n}\left(z^{-1}\right)
$$

where $F_{c k}$ is the control weighting without delay and $D_{k}$ is the plant time delay.

The combined white noise signal is defined by:

$$
Y_{f}\left(z^{-1}\right)=A_{f}^{-1}\left(z^{-1}\right) D_{f}\left(z^{-1}\right)
$$

where $Y_{f}$ is strictly minimum phase and $D_{f}$ is a strictly Schur polynomial.

The spectral factor is derived from the power spectrum of the combined noise signal and it is expressed as:

$$
Y_{f} Y_{f}^{*}=W_{r} W_{r}^{*}+W_{d} W_{d}^{*}
$$


In order to design the NFGMV it is necessary to cover the following conditions:

$$
A_{f} P_{c d} F_{0}+z^{-k} G_{0}=P_{c n} D_{f}
$$

and

$$
A_{f}^{-1} P_{c f}=P_{c n} A^{-1}
$$

Equation (9) is called the Diophantine equation with a solution $\left(\mathrm{G}_{0}, \mathrm{~F}_{0}\right)$ with $\left(\operatorname{deg} \mathrm{F}_{0}<\mathrm{k}\right)$.

All the assumptions and mathematical development can be found in (Grimble, 2003) giving as a result the next pseudo output function:

$$
\left.\left.\phi_{o}(t)=F_{0} \mathrm{~d} t\right)+z^{-k}\left(F_{c k} u(t)-F_{0} Y_{f}^{-1}\left(W_{k} u\right)(t)+\left(A_{f} P_{c d}\right)^{-1} G_{0} Y_{f}^{-1} d t\right)\right)
$$

and the control law defined for the minimum variance of the input is defined as

$$
u(t)=F_{c k}^{-1}\left(F_{0} Y_{f}^{-1}\left(W_{k} u\right)(t)-\left(A_{f} P_{c d}\right)^{-1} Y_{f}^{-1} e(t)\right)
$$

Finally, applying the GMV controller is possible to predict $k$ step ahead the pseudo-output and find the correct output for following the reference signal.

\section{NEURO-FUZZY MODELLING USING}

The Takagi-Sugeno-Kang (TSK) model uses the principle "divide and conquer" by using overlapping local linear models to approximate the behaviour in the operating range of nonlinear plants. These local linear models are linear models or piece-wise linear models that are locally stable and so all TSK model are stable (Jang, et. all., 1997; Babuška, 1998).

The TSK model uses an NARX (nonlinear autoregressive with exogenous input) input-output model. It defines the predicted output $y(t)$ at a future time instant and is part of the function of the regressor vector $z(t)$, consisting of a finite number of past inputs and outputs (Babuška, 1998):

$$
z(t)=\left[y(t-1), \cdots ; y\left(t-n_{y}\right), u(t), u(t-1), \cdots ; u\left(t-n_{u}\right)\right]
$$

where $n_{u}$ and $n_{y}$ define the dynamic order of the inputs and outputs delayed in order to cover the complete requirement for the adequate approximation of the nonlinear system.

The NARX model is defined by:

$$
\mathrm{y}(\mathrm{t})=\mathrm{f}(\mathbf{z}(t))
$$

This model is defined by means of the qualitative characteristic of the nonlinear system using Fuzzy rules. The Fuzzy rules are given as:

$$
\mathrm{R}_{\mathrm{i}} \text { : If } \mathbf{z}(\mathrm{t}) \text { is } \mathrm{A}_{\mathrm{i}} \text { then } \mathrm{y}_{\mathrm{i}}=\mathrm{a}_{\mathrm{i}}^{\mathrm{T}} \mathrm{z}(\mathrm{t})+\mathrm{b}_{\mathrm{i}} ; \mathrm{i}=1,2, \cdots, N
$$

where $\mathrm{R}_{\mathrm{i}}, \mathrm{A}_{i}, z(t), \mathrm{y}_{\mathrm{i}}, \mathbf{a}_{i}$ and $\mathrm{b}_{\mathrm{i}}$ are the $\mathrm{i}$-th fuzzy rule, the i-th fuzzy set, the regressor vector, the $\mathrm{i}$ th linear model, the $\mathrm{i}$-th consequent parameter vector and the i-th scalar offset, respectively. In addition, $N$ is the numbers of the rules.

The first-order TSK model of the nonlinear plant is expressed by:

$$
\begin{array}{r}
y(t)=\sum_{i=1}^{N} \gamma_{i}(\mathbf{z}(t)) y_{i} \\
y_{i}=\mathbf{a}_{i}^{T} \mathbf{z}(t)+b_{i}
\end{array}
$$

where $\gamma_{i}(\mathbf{z}(t)), y_{i}$ are the i-th normalized degree of fulfillment function (nonlinear function) and the i-th piece-wise linear model, respectively. By means of a mathematical manipulation it is possible to define the nonlinear model without delay as:

$$
y_{k}(t)=\left(W_{k} u\right)(t)=W_{o k}\left(W_{1 k} u\right)(t)=\sum_{i=1}^{N} \gamma_{i}(\mathbf{z}(t)) y_{i}
$$

For instance the equation (2) could be expressed as:

$$
y(t)=D_{k} \sum_{i=1}^{N} \gamma_{i}(\mathbf{z}(t)) y_{i}
$$

The Fuzzy model is found by training the NF system (Jang, et. all., 1997).

\section{THE ERROR AND CONTROL WEIGHTING}

The Error Weighting $\mathrm{P}_{\mathrm{c}}$ and Control Weighting $\mathrm{F}_{\mathrm{c}}$ were defined initially in the equations (5-6). The Error Weighting is expressed by:

$$
P_{c}=\frac{P_{c n}}{P_{c d}}=\frac{\left(k_{P 0}+k_{P}\right)\left(k_{I 0}+k_{I}\right)-\left(k_{P 0}+k_{P}\right) z^{-1}}{1-z^{-1}}
$$

where $k_{P 0}$ and $k_{I 0}$, are the proportional and integral gain of the PI controller that can initially stabilize the nonlinear plant, respectively. The variables $k_{P}$ and $k_{I}$ are the gains computed by the Fuzzy Self-Tuning Mechanism and they take the initial value of zero. 
The Control Weighting is expressed by:

$$
F_{c k}=\frac{F_{c n}}{F_{c d}}=\left(\rho_{0}+\rho\right) * \frac{\left(1-a z^{-1}\right)}{\left(1-b z^{-1}\right)}
$$

where $\rho_{0}, a$ and $b$ are constants for tuning the Control Weighting without delay $F_{c k}$. The variable $\rho$ is a gain introduced by the Self-Tuning Mechanism. The Error Weighting $P_{c}$ and Control Weighting $F_{c k}$ are nonlinear filters due to their adaptation on-line in each sample time.

\section{SELF-TUNING MECHANISM}

The Fuzzy Self-Tuning Mechanism of the controller has been founded in the expert knowledge to tune the gains in the PI controller (heuristically designed) for the Error Weighting $\mathrm{P}_{\mathrm{C}}$ and in the dynamic effect over the response of $\rho$ for the Control Weighting $\mathrm{F}_{\mathrm{c}}$. The expert knowledge was defined using Fuzzy rules with a structure of Mamdani's Fuzzy System [Jang , et. all., 1997; Babuška, 1998; Pinto, 2001a, 2001b]. The rules definition was obtained using the error signal $e(k)$ and increment of the error signal $\Delta e(k)$ as indicators of the dynamic behaviour of the output. The fuzzy rules for the Fuzzy Self-Tuning Mechanism have the following structure:

$$
\begin{aligned}
& \text { IF } e(k) \text { is } Z \text { and } \Delta e(k) \text { is } Z \\
& \text { Then } k_{p} \text { is } Z \text { and } k_{i} \text { is } Z \text { and } \rho \text { is } Z
\end{aligned}
$$

The Fuzzy Rules Base for the variables $k_{p}$ and $\rho$ are the same and are defined in the Table 1. The Fuzzy Rules Base for the variable $k_{I}$ is defined in the Table 2.

Table 1. Fuzzy Rule of the Variables e(k), $\Delta \mathrm{e}(\mathrm{k}), \mathrm{k}_{\underline{\mathrm{P}}}$ and $\rho$

\begin{tabular}{llllll}
\hline$\Delta e / e$ & $\boldsymbol{M N}$ & $\boldsymbol{N}$ & $\boldsymbol{Z}$ & $\boldsymbol{P}$ & $\boldsymbol{M P}$ \\
\hline $\boldsymbol{M} \boldsymbol{N}$ & $\mathrm{MN}$ & $\mathrm{MN}$ & $\mathrm{MN}$ & $\mathrm{N}$ & $\mathrm{MN}$ \\
$\boldsymbol{N}$ & $\mathrm{MN}$ & $\mathrm{N}$ & $\mathrm{N}$ & $\mathrm{N}$ & $\mathrm{MP}$ \\
$\boldsymbol{Z}$ & $\mathrm{MN}$ & $\mathrm{N}$ & $\mathrm{Z}$ & $\mathrm{P}$ & $\mathrm{MP}$ \\
$\boldsymbol{P}$ & $\mathrm{P}$ & $\mathrm{P}$ & $\mathrm{P}$ & $\mathrm{P}$ & $\mathrm{MP}$ \\
$\boldsymbol{M P}$ & $\mathrm{MP}$ & MP & MP & MP & MP \\
\hline
\end{tabular}

Table 2. Fuzzy Rule of the Variable $\mathrm{k}_{\mathrm{I}}$

\begin{tabular}{llllll}
\hline$\Delta e / e$ & $\boldsymbol{M N}$ & $\boldsymbol{N}$ & $\boldsymbol{Z}$ & $\boldsymbol{P}$ & $\boldsymbol{M P}$ \\
\hline $\boldsymbol{M} \boldsymbol{N}$ & $\mathrm{MP}$ & $\mathrm{MP}$ & $\mathrm{MP}$ & $\mathrm{MP}$ & $\mathrm{MP}$ \\
$\boldsymbol{N}$ & $\mathrm{MP}$ & $\mathrm{P}$ & $\mathrm{P}$ & $\mathrm{P}$ & $\mathrm{P}$ \\
$\boldsymbol{Z}$ & $\mathrm{P}$ & $\mathrm{Z}$ & $\mathrm{Z}$ & $\mathrm{Z}$ & $\mathrm{P}$ \\
$\boldsymbol{P}$ & $\mathrm{P}$ & $\mathrm{P}$ & $\mathrm{P}$ & $\mathrm{P}$ & $\mathrm{MP}$ \\
$\boldsymbol{M P}$ & $\mathrm{MP}$ & $\mathrm{MP}$ & $\mathrm{MP}$ & $\mathrm{MP}$ & $\mathrm{MP}$ \\
\hline
\end{tabular}

The variables $k_{p}, k_{i}$ and $\rho$ are nonlinear functions of the error and the difference of the error, expressed by the next equations:

$$
\begin{gathered}
k_{p}(k)=f(e(k), \Delta e(k)) \\
k_{I}(k)=g(e(k), \Delta e(k)) \\
\rho(k)=h(e(k), \Delta e(k))
\end{gathered}
$$

The comment above mentioned defines the equations (30) and (31) as nonlinear digital filters. The membership functions for the error signal $e(k)$, increment of the error $\Delta e(k)$, proportional gain $k_{P}$ and control weighting $\rho$ are shown in the Figure 2 . The membership function for the integral gain $k_{I}$ is shown in the Figure 3.

There are 25 fuzzy rules for each variable $\left(k_{p}, k_{i}\right.$ and $\rho)$. All the expert knowledge of the variables was obtained with the NFGMV developed in [19] and in order to tune the dynamic effect was observed over the output of the Nonlinear System.

For the variable $k_{i}$ positives values were selected because is the variable can only be positive.

In the Tables 1 and 2 names of the Fuzzy set are More Negative (MN), Negative (N), Zero (Z), Positive (P) and More Positive (MP). The fuzzy sets are defined in the Figure 2 and 3.

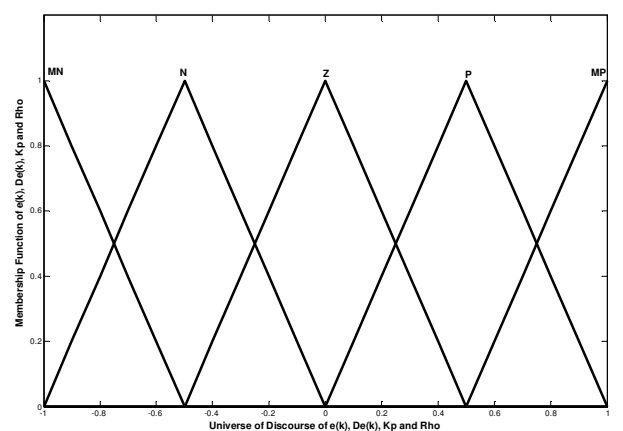

Figure 2. Membership Function of the Variables $e(k), \Delta e(k), k_{P}$ and $\rho$ 


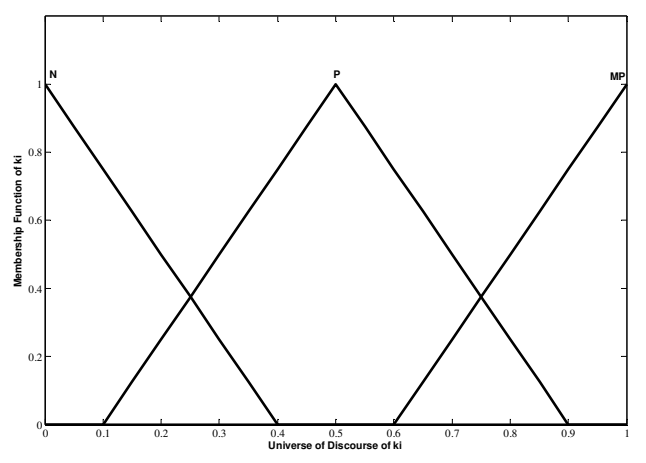

Fig 3. Membership Function of the Variable $k_{I}$

General Structure of the Self-Tuning Generalized Minimum Variance is shown in the Figure 4.

\section{SIMULATION EXAMPLE}

An irreversible exothermic reaction that occurs in the Continuous Stirred Tank Reactor with Cooling Jacket (CSTRCJ) model used to test the performance of the STNFGMV. The Nonlinear model of the Reactor is expressed by:

$$
\begin{array}{r}
\frac{d C_{a}(t+k d)}{d t}=\frac{q(t)}{V}\left[C_{a}^{0}(t)-C_{a}\left(t+k_{d}\right)\right] \\
-k_{0} C_{a}\left(t+k_{d}\right) \exp \left(-\frac{E}{R T(t)}\right)
\end{array}
$$

and

$$
\begin{array}{r}
\frac{d T(t)}{d t}=\frac{q(t)}{V}\left[T_{0}(t)-T(t)\right]-\frac{k_{0} \Delta H}{\rho C_{p}} C_{a}\left(t+k_{d}\right) \exp \left(-\frac{E}{R T(t)}\right) \\
+\frac{\rho_{c} C_{p c}}{\rho C_{p} V} q_{c}(t)\left[1-\exp \left(-\frac{h A}{q_{c}(t) \rho_{c} C_{p c}}\right)\right]\left[T_{C 0}(t)-T(t)\right]
\end{array}
$$

The energy and mass balance equations are defined in (35) and (36), respectively. The nominal parameter values in the model of the Reactor are: $C_{a}=0.1 \mathrm{~mol} \mathrm{~L}^{-}$

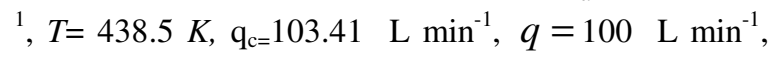
$C_{a 0}=1 \mathrm{~mol} \mathrm{~L}{ }^{-1}, T_{0}=T_{c 0}=350 K, V=100 \mathrm{~L}$, $h A=7.0 \times 10^{5} \mathrm{cal} \mathrm{min}^{-1} \mathrm{~K}^{-1}, k_{0}=7.2 \times 10^{10} \mathrm{~min}^{-1}, E / R$ $=1.0 \times 10^{4} \mathrm{~K}^{-1}, \Delta H=-2.0 \times 10^{5} \mathrm{cal} \mathrm{mol}^{-1}$ and $\rho=\rho_{c}=1.0 \times 10^{3} \mathrm{~g}$. The time delay of the concentration is $k=0.5 \mathrm{~min}$. The control objective is the concentration $C_{a}(t)$. The digital filter (PI controller) is defined by: $k_{p}=10$ and $k_{i}=10$.

The initial parameters for the STNFGMV controller are: $\mathrm{k}=3 ; \mathrm{A}_{\mathrm{f}}=1-0.8 \mathrm{z}^{-1} ; \mathrm{C}_{\mathrm{d}}=0.005 ; \mathrm{E}=0 ; \mathrm{k}_{\mathrm{p}}=9$;

$\mathrm{k}_{\mathrm{i} 0}=20 ; \mathrm{k}_{\mathrm{d} 0}=0 ; \rho_{0}=6.5 ; \mathrm{a}=0.785 ; \mathrm{b}=1$.

\subsection{The Neuro-Fuzzy Model of the Nonlinear Plant}

In order to find the adequate approximation of the free delay of the CSTRCJ was generated a random signal that covered all its operating range. After that, were compared the output of the correct model of the CSTRCJ and the Neuro-Fuzzy (NF) model. The NF model was training off-line and was expressed by the following fuzzy model (16 fuzzy rules):

Rule1: If $\mathrm{q}_{\mathrm{c}}(\mathrm{t})$ is in $1 \mathrm{mf} 1$ and $\mathrm{C}_{\mathrm{a}}(\mathrm{t}-1)$ is in $2 \mathrm{mf} 1$ and $\mathrm{C}_{\mathrm{a}}(\mathrm{t}-$ 2) is in $3 \mathrm{mf} 1$ and $\mathrm{q}_{\mathrm{c}}(\mathrm{t}-1)$ is in $4 \mathrm{mf} 1$ then $\mathrm{C}_{\mathrm{a} 1}=$ $0.6326 \mathrm{q}_{\mathrm{c}}(\mathrm{t})+0.05138 \mathrm{C}_{\mathrm{a}}(\mathrm{t}-1)-0.04837 \mathrm{C}_{\mathrm{a}}(\mathrm{t}-2)+0.0099882$ $\mathrm{q}_{\mathrm{c}}(\mathrm{t}-1)+0.03116$

Rule 16: If $\mathrm{q}_{\mathrm{c}}(\mathrm{t})$ is in $1 \mathrm{mf} 2$ and $\mathrm{C}_{\mathrm{a}}(\mathrm{t}-1)$ is in $2 \mathrm{mf} 2$ and $\mathrm{C}_{\mathrm{a}}(\mathrm{t}-2)$ is in $3 \mathrm{mf} 2$ and $\mathrm{q}_{\mathrm{c}}(\mathrm{t}-1)$ is in $4 \mathrm{mf} 2$ then $\mathrm{C}_{\mathrm{a} 1}=$ $0.00000921 \mathrm{q}_{\mathrm{c}}(\mathrm{t})+2.371 \mathrm{C}_{\mathrm{a}}(\mathrm{t}-1)-1.344 \mathrm{C}_{\mathrm{a}}(\mathrm{t}-2)-0.0003219$ $\mathrm{q}_{\mathrm{c}}(\mathrm{t}-1)+0.04551$

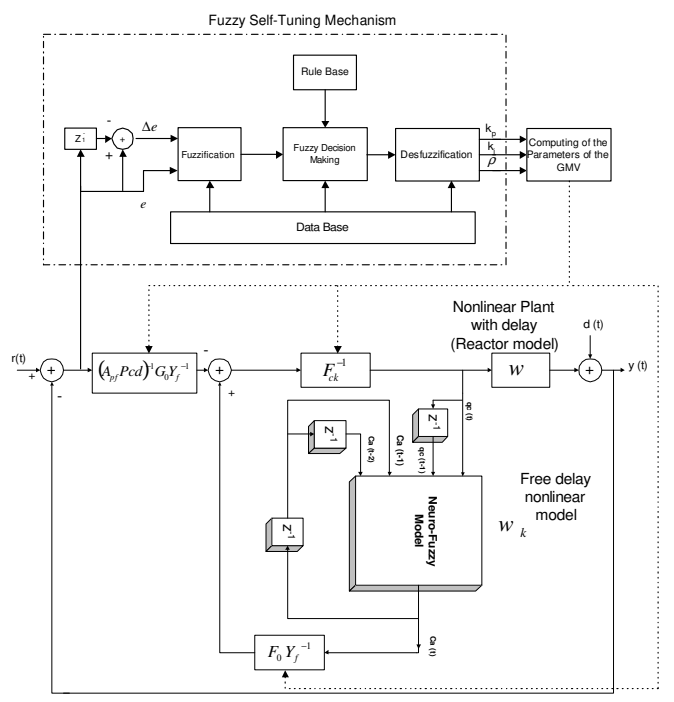

Fig. 4. Final Structure of the Self-Tuning Neuro-Fuzzy Generalized Minimum Variance

The Figure 4 shown the Final Structure of the SelfTuning Neuro-Fuzzy Generalized Minimum Variance formed by the Fuzzy Self-Tuning Mechanism and the Neuro-Fuzzy Generalized Minimum Variance.

\subsection{Tracking Reference Test}

In this test the reference signal was changed in the extremes of operation range of the CSTRCJ. The reference signal $\mathrm{Fc}_{\text {ref }}$ varies from to $0.1 \mathrm{~mol} \mathrm{~L}^{-1}$ to $0.125 \mathrm{~mol} \mathrm{~L}^{-1}$, from $0.125 \mathrm{~mol} \mathrm{~L}^{-1}$ to $0.1 \mathrm{~mol} \mathrm{~L}^{-1}$, and from $0.1 \mathrm{~mol} \mathrm{~L}^{-1}$ to $0.055 \mathrm{~mol} \mathrm{~L}^{-1}$ in intervals of 10 $\min$. The results of this test are shown in the figures 6 . 


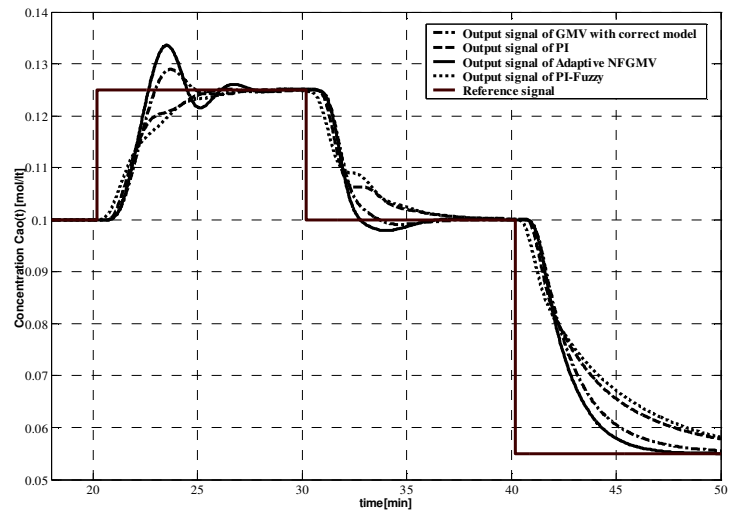

Figure 5. Output Signals of the Digital Filters and STNFGMV in the Tracking Reference Test

\subsection{Robustness Test}

In this test, the reference signal $\mathrm{Fc}_{\text {ref }}$ was varied from to $0.1 \mathrm{~mol} \mathrm{~L}^{-1}$ to $0.125 \mathrm{~mol} \mathrm{~L}^{-1}$, from $0.125 \mathrm{~mol} \mathrm{~L}^{-1}$ to 0.1 mol L $\mathrm{L}^{-1}$, and from $0.1 \mathrm{~mol} \mathrm{~L}^{-1}$ to $0.055 \mathrm{~mol} \mathrm{~L}^{-1}$ in intervals of $10 \mathrm{~min}$. The results of this test are shown in the figures 7 .

The variation of the nominal CSTR parameter are:

$V=95 \mathrm{~L}, h A=6.95 \mathrm{e} 5 \mathrm{cal} \mathrm{min}^{-1} \mathrm{~K}^{-1}, k_{0}=7.25 \times 10^{10} \mathrm{~min}^{-}$ ${ }^{1}, E / R=1.0 \times 10^{4} \mathrm{~K}^{-1}, \Delta H=-2.2 \times 10^{5} \mathrm{cal} \mathrm{mol}^{-1}$, $\rho=\rho_{c}=1.04 \times 10^{3} \mathrm{~g} \mathrm{~L}^{-1}$ and $C=C_{p c}=1.0 \times 10^{3}$ cal K ${ }^{-1}$.

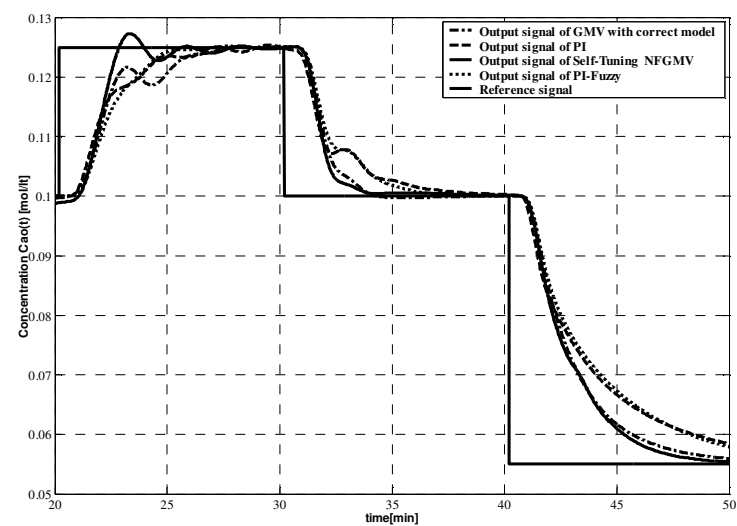

Fig. 6. Output Signals of the Digital Filters and STNFGMV in the Robustness Test

\section{CONCLUSIONS}

The STNFGMV simplifies the tuning of the NFGMV controller, because it is automatic. The dynamic behavior of the STNFGMV is better than the GMV controller with the correct model and the PI controller and the PI fuzzy controller. The proposed algorithm saves time in the tuning process of the controller.

\section{ACKNOWLEDGMENTS}

The first author is grateful to the financial support by the PROMEP scholarship in the Engineering Department at the Autonomous University of Tlaxcala in Mexico and the EPSRC.

\section{REFERENCES}

Åström K.J. (1979), Introduction to stochastic control theory, Academic Press, London.

Babuška, R. (1998), Fuzzy Modeling for Control, Kluwer Academic Publisher, International Series in Intelligent Technologies.

Babuška, R. and J. Oosterhoff and A. Oudshoorn and P. M. Bruijn (2002), Fuzzy self-tuning PI control of $\mathrm{pH}$ in fermentation, , .

Clark D.W. and R. Hastings-James (1971), Design of digital controllers for randomly disturbed systems, Proc. IEE, Vol. 118, No. 10, pp.1502-1506

Hastings-James R. (1970), A linear stochastic controller for regulation of systems with pure delay, University of Cambribge, Department of Engineering, Research Report No. CN/70/3.

Grimble M. J. (1988), Generalized minimum variance control law revisited, Optimal Control Applications and Methods, Vol. 9, pp.63-77.

Grimble M. J. (1993), $H_{\infty}$ Multivariable control law synthesis, IEE Proceedings, Control Theory and Applications, Vol. 140, No. 5, pp. 353-363.

Grimble M. J. (1994), Robust Industrial Control, Prentice Hall, Hemel Hempstead.

Grimble, M.J. (2003), Generalized Minimum Variance Control of Nonlinear Multivariable Systems, Internal report ICC-210, Industrial Control Centre, Univ. of Strathclyde.

Wang L.-X. (1997), A course in Fuzzy Systems and Control, ISBN:0-13-540882-2, Prentice Hall PTR.

Mudi Rajani K. [and] Pal Nikhil R. (1999), A Robust Self-Tuning Scheme for PI- and PD-Type Fuzzy Controllers, IEEE TRANSACTIONS ON FUZZY SYSTEMS, Vol. 7, No.1, February.

Pinto Castillo ,S. E. (2001), Control System with Adaptive Fuzzy Decoupling for the Regulation of Load of a Fossil Power Plant, Thesis of Master in Science in Electronic Engineering, CENIDET, Cuernavaca - Morelos, Mexico

Pinto Castillo, S. E. and G. Madrigal (2001), Adaptive Fuzzy Control System for the Load Regulation of a Fossil Power Plant, CICINDI, Mexico.

Jang J.-S. R. and C.-T. Sun and E. Mizutani (1997), Neuro-Fuzzy and Soft Computing- A Computational Approach to Learning and Machine Intelligence, ISBN 0-13-261066-3, Pearson Education editorial. 